\title{
Ketersediaan Sarana dan Prasarana Penunjang Pembelajaran Pendidikan Jasmani Olahraga dan Kesehatan
}

\author{
I Nyoman Tos Pasek Wiguna ${ }^{1 *}$, I Gst Lanang Agung Parwata ${ }^{2}$, I Ketut Semarayasa ${ }^{3}$ iD \\ ${ }^{123}$ Prodi Pendidikan Jasmani Kesehatan dan Rekreasi, Jurusan Pendidikan Olahraga, Fakultas Olahrga dan Kesehatan, \\ Universitas Pendidikan Ganesha, Singaraja, Bali \\ *Corresponding author: tos.pasek.wigunal,
}

\begin{abstract}
Abstrak
Ketersedian sarana dan prasarana yang baik adalah salah satu kunci keberhasilan proses pembelajaran di sekolah. Sehingga tiap sekolah perlu memiliki saran dan prasarana yang baik. Penelitian ini bertujuan untuk mengetahui ketersediaan sarana dan prasarana penunjang pembelajaran PJOK tingkat SMP se-Kecematan Banjar. Penelitian ini menggunakan jenis penelitian deskriptif kuantitatif dengan menggunakan metode survei karena penelitian ketersediaan sarana dan prasarana ini mendata beberapa sekolah yang mempunyai sarana dan prasarana penunjang pembelajaran yaitu khususnya mata pelajaran PJOK. Metode pengumpulan data yang digunakan adalah observasi dan dokumentasi di SMP se-Kecamatan Banjar. Jumlah populasi yang digunakan adalah 7 (tujuh) sekolah yaitu SMPN 1 Banjar, SMPN 2 Banjar, SMPN 3 Banjar, SMPN 4 Banjar, SMPN Satu Atap 1 Banjar, SMPN Satu Atap 2 Banjar, SMPN Satu Atap 3 Banjar. Pengumpulan data pada sarana dan prasarana dilakukan dengan cara mensurvei dari masing-masing sekolah, dan mengecek ketersediaan sarana dan prasarana sesuai dengan lembar observasi yang sudah dibuat. Hasil penelitian menunjukkan sebagai berikut. (1) Ketersediaan sarana penunjang pembelajaran PJOK di SMP Negeri se-Kecamatan Banjar jumlah total keseluran dari 7 sekolah tersebut yaitu 605 berkondisi baik 554 dengan rata-rata persentasenya 60,13\%, yang berkondisi buruk yaitu berjumlah 51 dengan rata-rata persentasenya $4.72 \%$. Kemudian dari segi status kepemilikan dari total keseluruhan jumlahnya 605 dengan rata-rata persentase $100 \%$ milik sendiri; (2) Ketersediaan prasarana penunjang pembelajaran PJOK di SMP Negeri se-Kecamatan Banjar jumlah total keseluruhan dari 7 sekolah tersebut yaitu 36 dengan persentase 100\% baik, dari segi status kepemilikan milik sendiri berjumlah 19 dengan rata-rata persentase $0,37 \%$ dan yang meminjam/menyewa berjumlah 17 dengan rata-rata persentase $25 \%$.
\end{abstract}

Kata Kunci: Sarana dan Prasarana PJOK, Instrumen PDPJOI

\section{Abstract}

The availability of good facilities and infrastructure is one of the keys to the success of the learning process in schools. So every school needs to have good advice and infrastructure. This study aims to determine the availability of facilities and infrastructure to support learning PJOK at the junior high school level in Kecamatan Banjar. This research uses quantitative descriptive research using survey methods because this research on facilities and infrastructure availability records several schools with learning support facilities and infrastructure, namely PJOK subjects. The data collection method used is observation and documentation in junior high schools in Kecamatan Banjar. The population used is 7 (seven) schools, namely SMPN 1 Banjar, SMPN 2 Banjar, SMPN 3 Banjar, SMPN 4 Banjar, SMPN Satu Atap 1 Banjar, SMPN Satu Atap 2 Banjar, One Roof Junior High School 3 Banjar. Data collection on facilities and infrastructure is carried out by surveying each school and checking the availability of facilities and infrastructure according to the observation sheet that has been made. The results of the study show the following. (1) Availability of supporting facilities for PJOK learning in public junior high schools Kecamatan Banjar, the total number of all 7 schools is 605 in good condition, 554 with an average percentage of $60.13 \%$, which in poor condition is 51 with an average percentage of $4.72 \%$. . Then in terms of ownership status, the total number is 605 with an average percentage of $100 \%$ own; (2) Availability of supporting infrastructure for learning PJOK in public junior high schools throughout Kecamatan Banjar, the total number of the 7 schools is 36 with a $100 \%$ good percentage, in terms of own ownership status, there are 19 with an average percentage of $0.37 \%$ and those who borrow /to rent is 17 with an average percentage of $25 \%$.

Keywords: PJOK Facilities and Infrastructure, PDPJOI Instruments

History:
Received: 24 September 2020
Revised: 1 Oktober 2020
Accepted: 26 Oktober 2020
Published: 7 November 2020




\section{Pendahuluan}

Sumber Daya Manusia (SDM) merupakan salah satu hal yang sangat penting dikembangkan dalam menghadapi persaingan di era globalisasi ini. Mengembangkan sumber daya manusida dapat dilakukan dengan beberapa faktor. Salah satunya yaitu dengan pendidikan. Melalui sektor pendidikan, manusia diharapkan mampu mewujudkan segala potensi yang ada didalam dirinya. Pendidikan sudah didapatkan sejak kita terlahir di dunia ini. Keluarga adalah pendidikan yang utama dan pertama yang didapatkan oleh anak, sebelum akhirnya nanti anak mengenal dunia pendidikan secara formal. Perkembangan zaman yang semakin maju, ditambah perkembangan globalisasi yang tidak terkendali mengharuskan membentuk pendidikan yang berkualitas. Kualitas pendidikan suatu negara mencerminkan kemajuan negara tersebut. Peningkatan kualitas pendidikan pada suatu negara harus dilaksanakan guna menciptakan sumber daya manusia yang memiliki daya saing yang tinggi dan berkualitas. Kualitas pendidikan dapat dicapai melalui proses pembelajaran yang berkualitas pula (Gede et al., 2020).

Pendidikan merupakan bagian integral dalam pembangunan suatu negara, proses pendidikan tidak dapat dipisahkan dari proses pembangunan itu sendiri, karena kedua komponen tersebut saling berhubungan satu sama lain. Salah satu unsur pendukung pembangunan adalah Sumber Daya Manusia (SDM). Untuk menciptakan SDM yang memiliki keterampilan dan keahlian yang tinggi diperlukan peran aktif dari pemerintah dan masyarakat dalam pembangunan dibidang pendidikan, baik bersifat formal maupun nonformal.

Pendidikan merupakan hal yang sangat penting bagi kehidupan manusia. Pendidikan bisa didapatkan dengan berbagai sumber seperti dilingkungan keluarga, dengan guru di sekolah, antar teman, melalui media, dan yang lainnya yang memberikan kita suatu ilmu yang bermanfaat bagi diri kita sendiri. dalam rangka mencapai suatu tujuan pendidikan nasional, slaah satu pembelajaran yang didapatkan oleh peserta didik di satuan pendidikan mulai dari Sekolah Dasar hingga Sekolah Menengah Atas adalah Pendidikan Jasmani Olahraga dan Kesehatan (PJOK). Menurut Faridah (2016) Pendidikan Jasmani, Olahraga dan Kesehatan merupakan bagian integral dari pendidikan secara keseluruhan, bertujuan untuk mengembangkan aspek kebugaran jasmani, keterampilan gerak, keterampilan berfikir kritis, keterampilan sosial, penalaran, stabilitas emosional, tindakan moral, aspek pola hidup sehat dan pengenalan lingkungan bersih melalui aktivitas jasmani, olahraga dan kesehatan terpilih yang direncanakan secara sistematis dalam rangka mencapai tujuan pendidikan nasional. Pendidikan jasmani, olahraga, dan kesehatan merupakan media untuk mendorong pertumbuhan fisik, perkembangan psikis, keterampilan motorik, pengetahuan dan penalaran, penghayatan nilai-nilai (sikap-mental-emosionalsportivitas- spiritual-sosial), serta pembiasaan pola hidup sehat yang bermuara untuk merangsang pertumbuhan dan perkembangan kualitas fisik dan psikis yang seimbang. Menurut(Junaedi, Anas, 2015), pendidikan jasmani, olahraga, dan kesehatan merupakan bagian dari pendidikan nasional yang harus melibatkan unsur-unsur penting berupa fikiran dan tubuh. Dimana semua aspek tersebut sangat berkaitan dalam kehidupan sehari-hari untuk menjadikan masingmasing individu agar menjadi baik.

Pendidikan Jasmani Olahraga Kesehatan (PJOK) di rasa perlu diberikan pada anakanak usia sekolah, karena untuk mendapatkan suatu kondisi badan sehat dan bugar di masa dewasa didapat melalui suatu proses yang panjang dari usia dini, yaitu usia sekolah sampai dewasa kelak. Tujuan pendidikan jasmani untuk membentuk anak yaitu sikap mental atau nilai, kecerdasan fisik dan keterampilan (psikomotorik), sehingga siswa akan dewasa dan mandiri yang nantinya akan dapat digunakan dalam kehidupannya (Suryobroto, 2004: 8).

Perencanaan pendidikan jasmani dilakukan secara seksama untuk memenuhi perkembangan, pertumbuhan, dan kebutuhan perilaku setiap anak. Maka pendidikan jasmani 
bukan hanya ditujukan untuk mengembangkan kemampuan psikomotorik, akan tetapi juga mengembangkan kemampuan kognitif dan afektif peserta didik (Paramitha \& Anggara, 2018).

Menurut Undang-Undang No. 20 tahun 2003, tentang Sistem Pendidikan Nasional, BAB XII Pasal 45: Setiap satuan pendidikan formal dan non formal menyediakan sarana dan prasarana yang memenuhi keperluan pendidikan sesuai dengan pertumbuhan dan perkembangan potensi fisik, kecerdasan intelektual, sosial, emosional, dan kejiwaan peserta didik. Keberhasilan pembelajaran PJOK, salah satunya dipengaruhi oleh faktor sarana dan prasarana olahraga yang tersedia dan dalam jumlah yang cukup memadai.

Kelancaran pembelajaran Pendidikan Jasmani Olahraga dan Kesehatan dapat diukur salah satunya dari ketersediaan sarana dan prasarana. Sarana dan prasarana yang memadai akan mencerminkan kualitas pembelajaran yang dilakukan, sehingga tujuan pendidikan akan tercapai dengan baik. Sebaliknya, sarana dan prasarana yang kurang memadai akan berdampak pada rendahnya mutu pendidikan, bahkan kurikulum tidak dapat berjalan. Suatu sarana dan prasarana akan memadai jika secara kualitas berdaya guna dan dari sisi kuantitas cukup untuk memenuhi kebutuhan pembelajaran seluruh siswa. Proses pembelajaran Pendidikan Jasmani Olahraga dan Kesehatan mutlak membutuhkan sarana dan prasarana untuk tercapainya tujuan, karena lebih menekankan pada pengembangan kemampuan motorik siswa (Tutus Eshananda Hars, Hermawan Pamot, 2014).

Dalam sistem pendidikan fungsi guru inilah sebagai pesan-pesan. Pendidikan yang harus dibantu dengan sarana dan prasarana pendidikan jasmani, agar proses belajar mengajar berlangsung efektif. Hal ini disebabkan karena materi pendidikan yang akan disampaikan beragam, yang harus mengikuti perkembangan ilmu dan teknologi yang semakin hari terus berkembang, dengan mulai meluasnya pengguna sarana dan prasarana maka faktor peserta didik mulai menjadi perhatian serius dari para guru penjasorkes karena merekalah yang akan menerima pendidikan secara langsung (Nursalam, 2016, 2013).

Adanya sarana dan prasarana yang memadai dalam suatu lembaga pendidikan yaitu sekolah-sekolah akan menunjang dan mempermudah seorang guru dan peserta didik dalam mempraktekan materi pelajaran olahraga. Oleh karena itu, sarana dan prasarana sangat berperan penting dalam pencapaian pembelajaran PJOK yang optimal. Sarana dan prasarana olahraga merupakan bagian yang sangat penting guna menunjang keberhasilan pembelajaran PJOK, karena dengan adanya sarana dan prasarana yang cukup tersedia maka pembelajaran PJOK akan lebih efektif dilakukan baik oleh guru maupun peserta didik. Guru akan mudah memberi pengarahan dan praktek suatu gerakan olahraga pada siswa secara langsung dengan menggunakan sarana yang ada, begitu pula dengan para siswa, mereka akan lebih giat dan semangat belajar olahraga 3 karena adanya lapangan dan alat- alat olahraga yang dapat mereka gunakan. Menurut Suryobroto (2004: 1) Sarana dan prasarana pendidikan jasmani salah satu faktor penunjang keberhasilan pendidikan jasmani dan merupakan unsur yang menjadi masalah dimana- mana, khususnya di Indonesia Marwah., dkk (2017) mengemukakan tentang efektivitas penerapan model pembelajaran sains yang menyatakan bahwa minimnya pembiasaan peserta didik untuk berpikir tingkat tinggi sehingga upaya yang dapat dilakukan adalah dengan memperbaiki kualitas pembelajaran yaitu memilih model pembelajaran yang inovatif, tepat guna dan tepat sasaran. Model pembelajaran yang dibutuhkan adalah model pembelajaran yang melibatkan peserta didik secara aktif, kritis, dan kreatif dalam menyelesaikan masalah di masyarakat atau lingkungan sebagai ajang mengaplikasikan keilmuwannya.

Dalam mata pelajaran PJOK sarana prasarana merupakan salah satu faktor utama penunjang keterlaksanaan kegiatan belajar mengajar, Kelengkapan sarana PJOK seperti peralatan bola sepak, bola voli, bola basket dan di bidang atletik seperti cakram, lembing dan untuk tolak peluru harus sebanding dengan jumlah siswa yang ada, sehingga proses kegiatan 
belajar mengajar berjalan dengan lancar dan tujuan pembelajaran dapat tercapai. Bukan hanya sarana prasarana saja namun peran tenaga pendidik juga sangat penting untuk meningkatkan kualitas mutu pendidikan di Indonesia melalui mata pelajaran Pjok (Cahya Pratama, 2018).

Mengingat sebagian besar proses pembelajaran pendidikan jasmani melibatkan aktivitas fisik maka keberadaan sarana prasarana menjadi sangat penting. Menurut Agus S. Suryobroto (2004) yang dikutip oleh Saryono \& Hutomo (2016, hal. 24) mengemukakan bahwa sarana adalah segala sesuatu yang diperlukan dalam pembelajaran pendidikan jasmani olahraga dan kesehatan yang mudah dipindahkan atau dibawa oleh pelakunya/ siswa (Widiastuti, 2019).

Menurut (Fatmawati, Nur. Andi Mappincara, 2019) sarana dan prasarana pendidikan yaitu segala perlengkapan/ fasilitas yang digunakan dalam proses pembelajaran baik yang bergerak maupun tidak bergerak seperti kursi, meja, ruang kelas dan lain-lain dalam rangka pencapaian tujuan pendidikan. Sarana dan prasarana merupakan faktor penting dalam menunjang keberhasilan pembelajaran PJOK tapi sarana dan prasarana ini juga menjadi masalah yang kerap kali ditemui di sebagian besar sekolah-sekolah di Indonesia. Ketersediaan sarana dan prasarana olahraga dirasakan sangat kurang dan tidak memadai baik dalam segi kuantitas maupun kualitasnya. Ada beberapa faktor yang menjadi penyebab minimnya sarana dan prasarana olahraga yang ada di sekolah-sekolah, seperti kurangnya anggaran dana untuk penyediaan sarana dan prasarana olahraga, atau dapat juga sempit/ atau kurangnya lahan sekolah, sehingga sekolah tidak mungkin membuat lapangan olahraga di area sekolah. Masalah tentang minimnya sarana dan prasarana olahraga di sekolah-sekolah, bukan masalah yang sederhana karena banyak faktor yang menjadi penyebabnya diantaranya terbatasnya alokasi dana untuk penyediaan sarana dan prasarana PJOK, dan jumlah sekolah yang banyak yang tersebar di seluruh Indonesia. Masalah tentang sarana dan prasarana PJOK hampir dialami oleh setiap jenjang sekolah baik itu jenjang sekolah SD, SMP maupun SMA, tetapi agar penelitian ini lebih fokus maka penulis membatasi subjek penelitian hanya Sekolah Menengah Pertama (SMP) yang ada di Kecamatan Banjar Kabupaten Buleleng. Menurut data dari kantor Dinas Pendidikan dan Kebudayaan Kabupaten Buleleng, Sekolah Menengah Pertama (SMP) yang ada di kecamatan Banjar berjumlah 7 sekolah. Dalam penelitian ini ke 7 SMP itu dijadikan sebagai sampel penelitian. Jadi penelitian ini merupakan penelitian populasi.

\section{Metode}

Jenis penelitian yang penulis pilih adalah merupakan penelitian deskriptif kuantitatif, dengan menggunakan metode Survei. Menurut (Kanca, 2010) penelitian deskriptif adalah penelitian yang bertujuan untuk mendiskripsikan secara sistematis, faktual dan akurat terhadap suatu populasi, atau daerah tertentu, mengenai sifat dan fakta-fakta tertentu. Dalam penelitian kuantitatif permasalahan yang diteliti sudah jelas, tetap, realitas dianggap tunggal, teramati pola pikir deduktif (Sugiono: 2018). Penelitian ini menggunakan metode survei dimana penulis menanyakan ke beberapa orang (responden) tentang data-data yang ingin penulis ketahui. Dengan menggunakan lembar observasi. Tujuan utama penelitian ini untuk mengetahui ketersediaan sarana dan prasarana penunjang pembelajaran PJOK tingkat SMP di kecamatan Banjar.

\section{Hasil dan Pembahasan}


Secara umum sarana dan prasarana olahraga di SMP Se-Kecamatan Banjar ini sudah cukup memadai. Hanya saja belum mendapatkan pengelolaan yang baik, artinya sarana dan prasarana disetiap sekolah tidak diperhatikan baik itu kuantitasnya maupun kualitasnya. Sehingga pada saat pembelajaran yang mengharuskan siswa untuk melakukan praktik terkadang tidak bisa dilakukan secara maksimal karena keterbatasan alat yang akan digunakan. Berikut merupakan tabel hasil penelitian mengenai kondisi sarana dan prasarana olahraga di SMP se-Kecamatan banjar beserta status kepemilikan dari sarana dan prasarana tersebut. Dari 37 jenis sarana yang terdiri dari bola sepak bola, bola voli, bola basket, bola kasti, keset/base, tongkat pemukul, bola softball, tongkat pemukul, keset/base, glove, bola tenis meja, bet, net, shuttle cock, raket, bola tenis lapangan, raket tenis lapangan, peluru, cakram, lembing, tongkat estafet, nomor dada, start block, bendera start, perata pasir atau cangkul, meteran, mistar lompat tinggi, body protector, target bela diri, matras, peti 39 loncat, simpai, tape recorder, papan tolak, kepet renang, pelampung, dan papan luncurdimiliki di masing-masing sekolah, setelah dijumlahkan total sarana dari tujuh SMP tersebut yaitu berjumlah 605. Dari 37 jenis sarana dapat diperoleh jumlah total seluruhnya yaitu sebanyak 605 buah yang berkondisi baik yaitu berjumlah 554 atau dengan rata-rata 14,97 dan memiliki persentase $60,13 \%$. sedangkan yang berkondisi buruk berjumlah 51 dengan rata-rata 1,37 dengan persentase $4,72 \%$.

Prasarana yang tersedia di SMP Negeri se-Kecamatan Banjar ini ada 6 jenis yang seluruhnya termasuk dalam fasilitas. Fasilitas yang tersedia yaitu area bermain dan olahraga, lapangan voli, lapangan basket, lapangan sepak bola, lapangan bulu tangkis dan bak lompat. Dari jumlah total atau keseluruhan, yaitu berjumlah 36 denga rata-rata 6 dan persentase $100 \%$ berkondisi baik. Dari segi status kepemilikan prasarana, fasilitas milik sendiri yaitu 19 dengan rata-rata 31,16 dan dengan rata-rta persentase $0,37 \%$, kemudian untuk fasilitas yang meminjam/menyewa berjumlah 17 dengan rata-rata 8,5 dan dengan rata-rata persentase $3 \%$.

Dari hasil penelitian yang sudah disebutkan diatas tidak semua sekolah memiliki sarana penunjang pembelajaran PJOK yang baik, masih saja ada barang yang rusak dan tidak bisa dipakai. Beberapa sarana yang di miliki oleh sekolah ada yang sudah memenuhi standar untuk jumlahnya ada juga yang belum memenuhi standar, di mana standar tersebut mengacu pada permendiknas No. 24 Tahun 2007 tentang sarana dan prasarana. Oleh karena itu, sarana penunjang pembelajaran PJOK seharusnsya mendapatkan pengelolaan dengan baik dari guru pengampu mata pelajaran tersebut. Pada status kepemilikan sarana penunjang pembelajaran PJOK di SMP seKecamatan Banjar dibedakan menjadi 2 kategori yaitu milik sendiri dan meminjam/menyewa. Dari 605 jumlah keseluruhan atau total sarana yang dimiliki dengan rata-rata 16,35 dan memiliki persentase $100 \%$ milik sendiri. Artinya pada setiap sekolah tidak ada meminjam atau menyewa sarana olahraga di sekolah lain atau di tempat olahraga yang lain.

Berdasarkan keterangan di atas dapat dilihat jika seluruh sekolah memiliki prasarana yang berkondisi baik, namun status kepemilikannya ada yang masih meminjam/menyewa. Di SMP Negeri se-Kecamatan Banjar masih dijumpai kurangnya perawatan terhadap fasilitas yang dimiliki di masing-masing sekolah seperti contohnya lapangan basket yang banyak lubang tidak segera diperbaiki karena jika tidak mendapatkan perhatian lebih lanjut akan berdampak kepada siswa ketika melakasanakan kegiatan pembelajaran. Perawatan fasilitas yang baik juga akan mempengruhi proses pembelajaran siswa karena jika fasilitas tersebut bersih maka bagi yang menggunakan juga akan merasa nyaman.

\section{Simpulan}


Berdasarkan hasil penelitian yang sudah dilakukan maka dapat disimpulkan bahwa ketersdiaan sarana dan prasarana penunjang pembelajaran PJOK di SMP Negeri seKecamatan Banjar secara keseluruhan dapat dikatakan sudah cukup baik, namun perlu pengelolaan yang baik. Secara lebih rinci sebagai berikut. (1) Ketersediaan sarana penunjang pembelajaran PJOK di SMP Negeri seKecamatan Banjar jumlah total keseluran dari 7 sekolah tersebut yaitu 605 berkondisi baik 554 dengan rata-rata persentasenya 60,13\%, yang berkondisi buruk yaitu berjumlah 51 dengan rata-rata persentasenya 4.72 persen. Kemudian dari segi status kepemilikan dari total keseluruhan jumlahnya 605 dengan rata-rata persentase $100 \%$ milik sendiri. (2) Ketersediaan prasarana penunjang pembelajaran PJOK di SMP Negeri seKecamatan Banjar jumlah total keseluruhan dari 7 sekolah tersebut yaitu 36 dengan persentase $100 \%$ baik, dari segi status kepemilikan milik sendiri berjumlah 19 dengan ratarata persentase $0,37 \%$ dan yang meminjam/menyewa berjumlah 17 dengan rata-rata persentase $25 \%$.

Sehubungan dengan hasil penelitian tentang Ketersediaan Sarana dan Prasarana Penunjang Pembelajaran Pendidikan Jasmani Olahraga dan Kesehatan Tingkat SMP seKecamatan Banjar Tahun 2020/2021 sebagian besar dapat dikatakan sudah baik namun, perlu ditingkat lagi dalam segi pengelolaannya agar lebih baik lagi. Maka untuk itu, penulis mengajukan saran kepada Pihak Sekolah Berdasarkan hasil penelitian yang sudah dilakukan disarankan kepada pihak sekolah SMP Negeri se-Kecamatan Banjar agar selalu melakukan peningkatan dalam pengelolaan sarana dan prasarana penunjang pembelajaran PJOK dengan 43 sebaik-baiknya, baik itu dalam ketersediannya, kondisinya maupun dari segi status kepemilikinnya agar nantinya semua dapat terkoordinir dengan baik. Disarankan agar peran serta kerjasama antar pemeritnah dengan pihak sekolah dapat berjalan dengan baik, sehingga nantinya tidaka da masalah dalam pengedaan sarana dan prasarana maupun pengelolaannya.

\section{Daftar Pustaka}

CAHYA PRATAMA, A. (2018). Survei Sarana Prasarana Pendidikan Jasmani Olahraga Dan Kesehatan, Sekolah Menengah Pertama Dan Sederajat. Jurnal Pendidikan Olahraga Dan Kesehatan, 6(3), 561-564.

Fatmawati, Nur. Andi Mappincara, S. H. (2019). Pemanfaatan dan Pemeliharaan Sarana dan Prasarana Pendidikan. PEMBELAJAR. Jurnal Ilmu Pendidikan, Keguruan, Dan Pembelajaran, 3(2), 115-121. https://doi.org/10.26858

Gede, I. D., Wirayasa, P., Darmayasa, I. P., \& Satyawan, I. M. (2020). Pengembangan Instrumen Penilaian Hasil Belajar Ranah Kognitif Model 4D Pada Materi Sepak Bola $\begin{array}{llll}\text { Berdasarkan } & \text { Kurikulum } & \text { 2013. } & \text { 8(3), }\end{array}$ https://ejournal.undiksha.ac.id/index.php/JJP/article/view/33760/17975

Junaedi, Anas, H. W. (2015). Survei Tingkat Kemajuan Pendidikan Jasmani, Olahraga, dan Kesehatan di SMA, SMK, dan MA Negeri Se-Kabupaten Gresik. Jurnal Pendidikan Olahraga Dan Kesehatan, 3(3), 834-842. https://jurnalmahasiswa.unesa.ac.id/index.php/jurnal-pendidikanjasmani/article/view/14367

Kanca, I. N. (2010). Metode Penelitian Pengajaran Pendidikan Jasmani dan Olahraga. Universitas Pendidikan Ganesha.

Nursalam, 2016, metode penelitian. (2013). Peranan Sarana Dan Prasarana Terhadap Motivasi Belajar Pada Pembelajaran Pendidikan Jasmani Olahraga Dan Kesehatan Di Sma Negeri 3 Banda Aceh. Journal of Chemical Information and Modeling, 53(9), 1689-1699.

Paramitha, S. T., \& Anggara, L. E. (2018). Revitalisasi Pendidikan Jasmani untuk Anak Usia Dini melalui Penerapan Model Bermain Edukatif Berbasis Alam. Jurnal Pendidikan Jasmani Dan Olahraga, 3(1), 41. https://doi.org/10.17509/jpjo.v3i1.10612 
Tutus Eshananda Hars, Hermawan Pamot, R. (2014). Journal of Physical Education, Sport, Health and Recreations. Journal of Physical Education, Sport, Health and Recreation, 4(2), 102-108. http://journal.unnes.ac.id/sju/index.php/peshr.

Widiastuti, W. (2019). Mengatasi Keterbatasan Sarana Prasarana Pada Pembelajaran Pendidikan Jasmani [Overcoming Facilities Limitations Affecting Physical Education Learning Activities]. Polyglot: Jurnal Ilmiah, 15(1), 140. https://doi.org/10.19166/pji.v15i1.1091. 